\title{
Asymmetric information about rivals' types in standard auctions: An experiment
}

\author{
James Andreoni ${ }^{\mathrm{a}}$, Yeon-Koo Che ${ }^{\mathrm{b}, *}$, Jinwoo Kim $^{\mathrm{c}}$ \\ ${ }^{a}$ Department of Economics, University of California-San Diego, CA, USA \\ ${ }^{\mathrm{b}}$ Department of Economics, Columbia University, 420 West 118th Street, Room 1016 IAB, New York, NY 10027, USA \\ ${ }^{\mathrm{c}}$ Department of Economics, Yonsei University, South Korea
}

Received 3 February 2005

Available online 13 November 2006

\begin{abstract}
This paper studies experimentally how information about rivals' types affects bidding behavior in firstand second-price auctions. The comparative static hypotheses associated with information about rivals enables us to test the relevance of such information as well as the general predictions of the auction theory, by providing an effective means to control for risk aversion and other behavioral motives that were difficult to control for in previous experiments. Our experimental evidence provides strong support for the theory, and sheds light on the roles of risk aversion and the spite motive in first- and second-price auctions, respectively. (C) 2006 Elsevier Inc. All rights reserved.
\end{abstract}

JEL classification: C72; C91; D44; D82

\section{Introduction}

This paper studies experimentally how bidders' knowledge of their rivals' types affects their behavior in standard auctions. The theoretical relevance of such knowledge has been established by Kim and Che (2004) (hereafter KC). ${ }^{1}$ They demonstrated how bidders react differently to the knowledge of their rivals' types in different auction formats. In a first-price auction with

\footnotetext{
* Corresponding author.

E-mail address: yc2271@ columbia.edu (Y.-K. Che).

1 Fang and Morris (2006) also found the relevance of information on rivals in standard auctions. Their model has two bidders with discrete valuations; each bidder obtains a noisy signal about his rival's valuation. Like KC, they find revenue non-equivalence between first-price and second-price auctions and allocative inefficiency of the first-price auction.
} 
ex ante symmetric bidders, knowledge about their rivals causes bidders to refine their bidding strategies based on that knowledge, so any asymmetry in the bidders' knowledge about their rivals leads to an inefficient allocation as well as lower revenue than when the bidders have symmetric information about their rivals. By contrast, bidders' knowledge about rivals should have no effect in a second-price sealed-bid auction since they have a dominant strategy of bidding their valuations. In fact, $\mathrm{KC}$ have identified precise equilibrium strategies in a number of different information structures regarding rival types, when the types are uniformly distributed. We test these predictions.

Testing these predictions can serve several useful purposes. First, bidders' knowledge of rivals' types as well as its asymmetry is quite relevant in various auction settings, such as procurement contests, privatization, and corporate takeover. These auctions typically attract bidders with a wide range of backgrounds, differing in previous industry operation as well as in previous dealings with similar auctions. These differences are likely to generate asymmetry in bidders' abilities to assess their rivals' willingness to pay. For instance, a radio frequency license auction may attract so-called incumbent firms as well as relative newcomers; and the incumbents are likely to know more about other incumbents' capabilities than those of the newcomers. Empirical testing of the hypothesized effects will help us not only to learn about the bidding behavior but also to draw relevant policy implications in these settings. ${ }^{2}$

Second, and perhaps more importantly, the comparative statics hypotheses on how bidders react to different rival information provide additional restrictions on the theory unavailable in extant studies, thus enabling us to test more effectively the underlying behavioral paradigm itselfnamely whether bidders behave according to the Nash hypothesis. For instance, observations on how bidders adjust their strategies to different information on their rivals in a first-price auction can produce much sharper identification on whether bidders follow the Nash paradigm than previous experiments measuring the degree of bid shading or ones comparing the revenue between first- and second-price auctions. Examining the amounts of bid shading may not effectively distinguish the Nash behavior from, say, an alternative hypothesis that bidders follow a naive rule of thumb. Likewise, revenue comparison across auction formats may be subject to risk aversion and other behavioral motives that may affect the formats differently but are difficult to control for in an empirical setting. ${ }^{3}$ Further, the celebrated dominance hypothesis in a second-price auction can be tested more effectively when bidders are subject to additional information that should not affect their behavior if the hypothesis were true.

Finally, our rich comparative statics hypotheses can provide a better handle on such uncontrollables as bidder risk aversion or "behavioral" motives, and may thus clarify some of the anomalies observed in the past auction experiments. In particular, they reported overbidding in first- and second-price auctions relative to theoretical predictions. While bidders' risk aversion and their strategic mistakes or their "spite" motive have been blamed for the overbidding respectively in the first- and second-price auctions, there has been disagreement in the literature on

\footnotetext{
2 In addition to the standard policy instruments such as reserve prices and entry fees, the auctioneer may have some control over what information can be publicly disclosed. For instance, in a corporate takeover, the degree to which the target firm's financial status and dealings are revealed can be a choice variable. A similar choice is available in the sale of real estate, e.g., condominiums, in terms of the specific location, blue prints and orientation. The information on these aspects often has different implications for different bidders, much as assumed in the model of KC. See Bergemann and Pesendorfer (2003) and Eso and Szentes (2006) on the theoretical analysis of the issue.

3 Risk aversion may affect the revenue performance of a first-price auction, but not that of a second-price auction (given the dominance of bidding one's valuation in the latter). Meanwhile, a loser's ability to influence the selling price in the latter may lead to "spite"-motivated overbidding there, but not in a first-price auction.
} 
their effects. ${ }^{4}$ The change in information about rivals can serve as a useful instrument to control for the presence of risk aversion in the case of first-price auction and to clarify the validity of the competing explanations for overbidding in the second-price auction.

To test these hypotheses properly, not only must the researcher have clear knowledge of the information bidders have about their rivals, but the nature of the bidders' information must also conform to that assumed in the model. While these features are unlikely to be met in real auctions (and the data), a lab experiment can easily be designed to replicate the precise information structures assumed in the model. For this reason, we adopt a lab experiment as a method of test.

In the experiment, subjects play a sequence of auctions with increasingly more information about their rivals' types. More specifically, each round of an experiment selects a set of four bidders to play three auction games. The profile of valuations stays the same for each auction, but the information changes. In Auction 1, each bidder is informed only of his own valuation (and only of the distributions of their rivals' valuations). In Auction 2, while keeping the same valuation profile, each set of four bidders is partitioned into two "knowledge" groups of two, and an auction game is played with each bidder informed of his within-group rival's valuation as well as his own. Finally, in Auction 3 bidders are informed of valuations of all four bidders, again with the same valuation profile. The information about winners for all three auctions is announced only after the bidders complete the entire 3 auction cycles, so that no inference about their rivals' valuations (other than the ones disclosed by design) can be made. These experiments were performed for both first- and second-price auctions.

We test two sets of hypotheses, one for bidders' equilibrium behavior and the other for revenue and efficiency performance of the standard auctions. First, to test for the bidding behavior in the first-price auction, we conduct a structural regression analysis based on the explicit equilibrium bidding function obtained for the uniform distribution case. As for the second-price auction, a reduced form regression, where bids are regressed on the varying set of bidders' private information, is employed to test whether knowledge of rivals' valuations affects the bidding behavior.

Another set of hypotheses deals with the effect on the expected revenue and allocative efficiency. In a first-price auction, revenue as well as efficiency varies non-monotonically, dropping initially as bidders' information about rivals shifts from no information (Auction 1) to information about one rival (Auction 2) but rising thereafter when it shifts to information about all rivals (Auction 3). By contrast, no change in revenue or efficiency is predicted for the second-price auction. Given the simple and explicit form of equilibrium bidding function found in the case of the uniform distribution and risk neutral bidders, we can obtain quantitative measures of revenue and surplus for both auction formats. These measures are then used to check how closely the theory approximates the real data.

These hypotheses receive strong support from our experimental data. The observed patterns of bid shading relative to own valuations as well as of the adjustment of bids to the learning of rivals' types in a first-price auction matched closely those predicted by the theory. The experiment on the second-price auction lends support to the dominance hypothesis, as a large portion of subjects bid close to their valuations and do not display much sensitivity to the information about their rivals. As with the extant auction experiments, some overbidding was observed in

\footnotetext{
4 See Kagel (1995) for the debates and tests conducted on these issues. While the spite motive has not been addressed recently (apart from this paper), recent contributions have supported risk aversion, conditional on utility of the constant relative risk averse form, $u(\pi)=\pi^{r}$. Chen and Plott (1998) and Goeree et al. (2002) find $r \approx 0.5$. Reanalyzing the data of Dyer et al. (1989), Bajari and Hortacsu (2004) find $r \approx 0.25$. Using data from US Forest Service auctions, Campo et al. (2002) find $r \approx 0.6$.
} 
both formats, while some underbidding was observed in a second-price auction. Overbidding was more pronounced in a first-price auction when the valuation of the main competitor is unknown, which lends credence to the view that risk aversion is a source of overbidding. In a secondprice auction, underbidding dissipates in later rounds, indicating that strategic mistakes may have been a factor, but overbidding remained a pattern throughout. Moreover, overbidding is more pronounced when a bidder is convinced of losing and in a position to set the selling price, and concentrated at levels slightly below the highest valuation (i.e., the likely winner's bid). This pattern suggests the presence of a "spite" motive behind overbidding.

The rest of the paper is organized as follows. The next section reviews the theoretical results and presents testable hypotheses. Section 3 describes an experiment designed to test them. Section 4 reports experimental results. Section 5 concludes.

\section{Theory review and testable hypotheses}

A unit of a good is auctioned off to $n \geqslant 2$ risk-neutral bidders each with a valuation drawn uniformly from $[0,1]$. The valuation distribution is common knowledge to all bidders, but bidders may know the realized valuations of some rivals. Formally, bidders are partitioned into "knowledge groups" such that they know the realized valuations of the rivals within the same group, while they know only the distribution of types for bidders outside their group. This partition model is convenient for modeling different information structures regarding rivals' types. Suppose that $n$ bidders are partitioned into $k$ knowledge groups of $m$ bidders in each group, a situation called a " $k \times m$ partition." 5

For the current experiment, we assume $n=4$ and focus on three partition structures: $4 \times 1$, $2 \times 2$ and $1 \times 4$. The $4 \times 1$ partition, labeled Auction 1, involves no information about rivals and corresponds to the standard assumption invoked in the auction literature; the $2 \times 2$ partition, labeled Auction 2, involves an intermediate situation in which each bidder knows the valuation of only one rival; and $1 \times 4$ partition, labeled Auction 3, involves full information about rivals' valuations, i.e., a Bertrand game. Of particular interest is how bidders react as more information about rivals is revealed, via a shift from Auction 1 to Auction 2, and from Auction 2 to Auction 3.

For each partition, we study a Bayes-Nash equilibrium of each auction game in undominated strategies. Excluding weakly dominated strategies serves the purpose of pruning out unreasonable equilibria present in a Bertrand game and a second-price auction. ${ }^{6}$ The following hypotheses are derived from KC (2004).

\subsection{Equilibrium behavior in the first-price auction}

In a first-price auction, bidders shade their bids to obtain a surplus upon winning, and the amount of shading depends on rivals' bidding behavior. If the rivals bid aggressively, then a bidder may not shade much, for instance. By the same token, bidders facing rivals with high

\footnotetext{
$5 \mathrm{KC} \mathrm{(2004)} \mathrm{consider} \mathrm{an} \mathrm{arbitrary} \mathrm{partition} \mathrm{structure,} \mathrm{including} \mathrm{possibly} \mathrm{an} \mathrm{asymmetric} \mathrm{structure.} \mathrm{Assuming} \mathrm{symmetry}$ in the partition structure yields a closed-form characterization of equilibrium, which is convenient for the purposes of an experiment.

6 A Bertrand game has equilibria in which the stronger bidder bids strictly higher than the valuation of second-highest valuation bidder, for fear of the latter bidding above his valuation. Meanwhile, a second-price auction admits equilibria in which the strongest bidder loses to a weaker bidder bidding strictly higher than his valuation. Both types of equilibria are supported by weakly dominated strategies, however.
} 
valuations may bid more aggressively. For this reason, knowing rivals' types leads bidders to alter the extent to which they shade their bids. This is the main feature of equilibrium prediction described below.

For the case of a $k \times m$ partition with valuations drawn uniformly from [0,1], we have a closed-form characterization for the equilibrium bidding strategies. To describe the latter, it is useful to distinguish a bidder with the highest valuation and the one with the second highest valuation in a group, respectively called "leader" and "follower." In the trivial case $m=1$, each group has only one bidder, so he will be treated as a leader. We begin with the leader's strategy ${ }^{7}$ :

First-Price Bidding by Leaders (FPBL). Consider a $k \times m$ partition such that $n=k \times m$. In a first-price auction, a leader with valuation $v_{\ell}$ facing a follower with valuation $v_{f}$ bids

$$
\max \left\{\frac{n-m}{n-m+1} v_{\ell}, v_{f}\right\}
$$

where $v_{f}$ is set equal to 0 when $m=1$.

The proof of this proposition can be found in Appendix A. According to this proposition, a leader bids between his valuation and the second highest valuation within his group in a particular fashion: he combines the bidding strategy familiar from the standard first-price auction with a Bertrand behavior. Specifically, a leader follows an unconstrained bidding strategy, $\beta_{\ell}^{m}\left(v_{\ell}\right) \equiv \frac{n-m}{n-m+1} v_{\ell}$, which depends only on his valuation, except when the follower's valuation, $v_{f}$, "binds" in the sense that $\beta_{\ell}^{m}\left(v_{\ell}\right)$ falls short of $v_{f}$. In the latter case, the leader adopts the Bertrand behavior, matching the following valuation precisely. ${ }^{8}$ Interestingly, the unconstrained strategy $\beta_{\ell}^{m}\left(v_{\ell}\right)$ is precisely the strategy a bidder would adopt in a standard first-price auction with $n-m+1$ bidders, with no information about rivals (i.e., $(n-m+1) \times 1$ partition). That is, if "not constrained" by the group members, a leader acts as if there are only $n-m$ outsider rivals, completely ignoring the $m-1$ within-group rivals.

Inspecting how the leader's bidding strategy changes with the information structure reveals several testable hypotheses. Fixing $n=4$, we can write the leader's equilibrium strategy in auction $a=1,2,3$ as

$$
b_{\ell}^{a}\left(v_{\ell}, v_{f}\right)=\max \left\{B_{1}^{a} v_{\ell}, B_{2}^{a} v_{f}\right\} .
$$

Then, FPBL yields the following predictions on the coefficients, $B_{1}^{a}$ and $B_{2}^{a}$.

FPBL 1. The coefficients $B_{1}^{a}$ and $B_{2}^{a}$ in a leader's equilibrium strategy take the following values in Auction $a=1,2,3$ as follows ${ }^{9}$ :

\begin{tabular}{c|ccc}
\hline & $a=1$ & $a=2$ & $a=3$ \\
\hline$B_{1}^{a}$ & $\frac{3}{4}$ & $\frac{2}{3}$ & 0 \\
$B_{2}^{a}$ & $n / a$ & 1 & 1 \\
\hline
\end{tabular}

\footnotetext{
7 This assumes that ties are broken in favor of the leader (see KC, 2004), for a similar reason that the tie-breaking rule is adopted in a Bertrand game. This tie-breaking rule is not necessary, though, if the valuations are discrete, as is the case with our experiment. For this reason, the issue of the tie-breaking rule does not arise in our experiment; and we simply adopt the usual random tie-breaking rule.

8 When the valuation support is discrete, as in our experiment, a Bertrand behavior will be to match the follower's valuation or bid a unit above that valuation, depending on the fineness of the support.

9 Auction 1 has no follower, so $B_{2}^{1}$ is not well defined.
} 
Notice that a shift from Auction 1 to Auction 2 causes group leaders to bid less aggressively, unless constrained by the followers' valuations.

FPBL further generates implications on how the leader would react to knowledge of the follower's valuation once it becomes known to him.

FPBL 2. For Auction $a=2,3$, the following holds:

$$
\begin{aligned}
& b_{\ell}^{a}\left(v_{\ell}, v_{f}\right)<B_{1}^{1} v_{\ell} \quad \text { if } B_{1}^{1} v_{\ell}>v_{f}, \\
& b_{\ell}^{a}\left(v_{\ell}, v_{f}\right)=v_{f}>B_{1}^{1} v_{\ell} \quad \text { if } B_{1}^{1} v_{\ell}<v_{f} .
\end{aligned}
$$

According to FPBL2, if a bidder realizes that he bid higher than the highest rival valuation in his group in Auction 1 (i.e., without knowing the rival valuations), he adjusts his bid downward in Auctions 2 and 3 (i.e., after realizing those rival valuations). On the other hand, if he realizes that he bid less than some valuations of his within-group rivals and his valuation exceeds these rival valuations, then he adjusts his bid upward to match the highest within-group rival valuation. As will be seen, the design of our experiment will enable us to test this particular hypothesis.

FPBL can also be tested based on its implication on the correlation between a leader's bid and a follower's valuation:

FPBL 3. An Auction 2 leader's Auction 2 bid is more highly correlated with the valuation of the follower in his group than is his Auction 1 bid. The Auction 3 leader's bid is more highly correlated with the Auction 3 follower's valuation than his own valuation.

Despite the independence in valuation distribution, there is a selection-induced correlation between an Auction 2 leader's Auction 1 bid and his follower's valuation: The higher the leader's valuation, the higher the within-group follower's valuation is likely to be, simply because the support of the latter is chosen conditionally on the former's valuation. Since the former's equilibrium bidding strategy in Auction 1 is monotone increasing in his valuation, there exists a positive correlation between the two values. This correlation is again present in Auction 2 between the two values, but there is a tighter correlation due to the Bertrand effect, which arises whenever the follower's valuation is binding. In Auction 3, the correlation coefficient between the leader's bid and the follower's valuation becomes 1, implying that the leader's bid is more highly correlated with the follower's valuation than his own valuation. These relationships between correlation coefficients provides an additional way of testing if a leader's bidding strategy adjusts to his rival information according to the theoretical predictions.

Next, we turn to the equilibrium predictions for the follower.

First-Price Bidding by Followers (FPBF). In a first-price auction, a follower bids no higher than his valuation in Auctions 2 and 3.

A follower's equilibrium strategy is not pinned down in the Bertrand-type situation wherein the leader bids the follower's valuation, in both Auctions 2 and 3. It is an equilibrium behavior for the follower to bid below his valuation with some probability, since the follower earns zero payoff in equilibrium and the leader will not be tempted to deviate as long as the follower puts 
a sufficient probability mass/density close to his valuation. ${ }^{10}$ In Auction 2, if a group leader bids strictly above the follower's valuation (i.e., the latter is not binding), any bid below the follower's valuation can be an equilibrium response. Such a multiplicity should be taken into account when interpreting experimental data. This multiplicity issue aside, a Bertrand game presents an additional difficulty in interpreting the follower's behavior. As is well known, a follower does not have a unique best response (even when he has a unique equilibrium response); any bid below or equal to his valuation would be optimal.

Remark 1 (Risk Aversion). One element of the theory that cannot be replicated in an experiment is the risk neutrality of bidders, for the risk attitudes of the subjects cannot be controlled. ${ }^{11}$ Nevertheless, our hypotheses provide a better handle on this issues than in the previous studies. First, Bertrand behavior is not subject to bidders' risk attitudes, so the follower's behavior in FPBF and the dependence of a leader's bid on the follower's valuation-coefficients $B_{2}^{2}$ and $B_{2}^{3}$ - are robust to the risk aversion issue. Likewise, the qualitative response by a leader to the rival information, as described in FPBL2 and FPBL3, are robust to the bidders' risk attitudes. The only elements of the predictions that are susceptible to risk aversion are the two coefficients $B_{1}^{1}$ and $B_{1}^{2}$, i.e., the dependence of a leader's bid on his own valuation in Auctions 1 and 2. Risk aversion of a bidder will imply overbidding relative to the theoretical predictions in this case, thus higher estimated values of the coefficients than the respective predictions, $3 / 4$ and $2 / 3$. In fact, the pattern of overbidding can help reveal its source in testing risk aversion, for instance, against a possible alternative hypothesis of a "joy-of-winning bias." If risk aversion is at work, then bidders face more uncertainty in Auctions 1 and 2 relative to Auction 3, so the overbidding would be more pronounced in former auctions than in the latter, whereas the joy-of-winning hypothesis would imply no such pattern of overbidding. In fact, the latter theory may imply even deviations from the Bertrand behavior.

\subsection{Equilibrium behavior in the second-price auction}

In a private value environment, it is well known that bidders in a second-price auction (or English auction) have a weakly dominant strategy of bidding their valuations. The weak dominance of this "truthful bidding" means that, unlike in a first-price auction, information about rivals' valuations should have no impact on bidding behavior in a second-price auction.

Second-Price Bidding (SPB) (Truthful Bidding). In a second-price auction, the bidders bid their valuations, regardless of the partition structure.

\footnotetext{
10 In fact, given a random tie-breaking rule and a continuous strategy space, any equilibrium response by the follower must involve randomizing below his valuation (see Blume, 2003). Given a discrete strategy space (which is more relevant for our experiment), bidding one's valuation with probability one can be supported as an equilibrium (if the leader bids a unit above it with probability one), but bidding below his valuation can be also supported as an equilibrium.

11 There is considerable debate in experimental circles about whether this is in fact true. An influential paper by Roth and Malouf (1979) provides a methodology for inducing risk neutrality by paying subjects with lottery tickets over a binary lottery, rather than cash. The reasoning is that even risk averse people are risk neutral in probability. Very few studies have directly tested the efficacy of the Roth-Malouf technique. Selten et al. (1999) summarize the literature and conduct a direct test. They are harshly critical of the method, suggesting it makes inference even more difficult.
} 
As mentioned above, subjecting bidders to different information about rivals provides a tighter identifying restriction than has been available in past experiments, thus helping to test the validity of the dominance hypothesis.

Remark 2 (Strategic Mistakes, Spite Motive, Joy of Winning). Overbidding has been observed in previous experiments of second-price auctions (e.g., Kagel et al., 1987; Kagel and Levin, 1993). Such deviations from weakly dominant strategies may result from computational mistakes on the part of the bidders or from their bias toward winning. For instance, Kagel et al. found the disappearance of overbidding with English auctions, which would suggest that difficulty of figuring out the Vickrey auction as a reason for observed overbidding in the second-price auction. Alternatively, the deviations may be attributed to behavioral motives such as "spite." For instance, Morgan et al. (2003) suggested that bidders may have an incentive to hurt their rivals by raising bids above their valuations in case they lose. Finally, the overbidding can be simply explained as extra utility premium subjects may attach to winning an auction ("joy of winning"). ${ }^{12}$ Our model can provide an additional opportunity to gain better understanding of the source of overbidding to the extent that overbidding is a systematic phenomenon. Different theories of overbidding have different predictions about when a bidder is more likely to overbid and how he/she would do so. For instance, spite will be a likely motive for overbidding, if overbidding is more pronounced

(1) when a bidder is a follower-namely one who is convinced of losing and is in a position to hurt the winner,

(2) when a leader's valuation is known (since a follower can safely inflate the selling price without risking an unprofitable win), and

(3) when a follower bids slightly less than the leader's valuation.

No such pattern of overbidding relative to a bidder's identity or to the knowledge about rival types is expected if the reason behind overbidding were strategic mistakes. Further, the 'strategic mistakes' theory would imply that the overbidding will abate as bidders gain more experience whereas the spiteful overbidding need not diminish with experience. Finally, joy of winning will be evidenced by bids above leaders' valuations. These aspects of behavior will be examined in Section 4.

\subsection{Revenue and surplus performances}

We can draw revenue and surplus implications from the bidding behavior presented above. In a second-price auction, SPB immediately implies the following hypothesis:

Second-Price Revenue and Surplus (SPRS). A second-price auction generates the same full surplus and revenue irrespective of the partition structure.

By contrast, in a first-price auction the dependence of a bidder's equilibrium bid on his withingroup rivals' valuations means that the information about rivals' types has a nontrivial impact on the surplus and revenue. Clearly, in Auction 1 (no information about rivals) and Auction 3 (full

12 In a recent experiment of second-price auction, based on the model of Fang and Morris (2006), Cooper and Fang (2006) observe overbidding behavior and ascribe it to a (modified) joy of winning motive. 
information about rivals) the good is allocated efficiently and the revenue equals the secondhighest valuation. In Auction 2 (i.e., $2 \times 2$ partition), the leaders of the two groups will likely bid different amounts, even when they have the same valuation, if they face within-group rivals with different valuations. Hence, the allocation is generally inefficient, and KC (2004) show that this inefficiency leads to a lower expected revenue than in Auction 1 or 3. The result is summarized as follows ${ }^{13}$ :

First-Price Revenue and Surplus (FPRS). A first-price auction generates the same full surplus and revenue in Auction 1 and Auction 3. The total surplus and expected revenue are strictly lower in Auction 2.

FPRS implies that total surplus and revenue vary non-monotonically with a shift from Auction 1 through Auction 2 to Auction 3. They first drop when the partition structure shifts from "no information about rivals" to "information about some rivals," and they rise back to the original levels with the shift to "full information about rivals."

Remark 3. Bidder risk aversion will affect the revenue and surplus implications in a first-price auction. As mentioned earlier, though, the effect varies across the information structures. Risk aversion should have no effect in Auction 3, will cause leaders to overbid when followers' valuations are not binding in Auction 2, and it will cause all bidders to overbid in Auction 1. Consequently, even with a bidder risk aversion the prediction of a revenue decrease associated with a shift from Auction 1 to Auction 2 should not be affected, whereas the predicted revenue rise when moving from Auction 2 to Auction 3 may be dampened or reversed. Finally, overbidding may arise in a second price auction, for the reason described above. If a spite motive is present, the overbidding will be more pronounced as more information about rivals becomes available, causing the revenue to rise with a shift from Auction 1 to Auction 2, and to Auction 3.

\section{Experiment design}

Each session of the experiment involved 20 subjects playing 30 rounds of auction games. We ran two sessions each of the first- and second-price auctions, for a total of 80 subjects. The subjects were volunteers from undergraduate economics courses. Each session lasted less than two hours. Subjects were each given $\$ 4.96$ in their earnings account at the start of the experiment (62 tokens, valued at $\$ 0.08$ each), to which their earnings in the auctions were added or subtracted. Subjects earned on average $\$ 32.66$ (s.d. $\$ 12.45$ ), ranging from a maximum of $\$ 70.84$ to a minimum of $\$ 2.96$. All subjects finished the experiment with positive balances in their earnings accounts.

In each round, the 20 subjects were randomly divided into 5 cohorts of 4 bidders. These four bidders then played Auction 1 ( $4 \times 1$ partition), Auction $2(2 \times 2$ partition $)$, and Auction $3(1 \times 4$

\footnotetext{
13 It is well known that first- and second-price auctions are revenue equivalent in Auctions 1 and 3. It then follows from above that the second-price auction yields higher revenue than the first-price auction in Auction 2 (see KC, 2004). While this latter result can be tested in principle, the magnitude of revenue difference may not be sufficiently large to ensure a meaningful test. Moreover, revenue comparisons across different formats are susceptible to risk aversion and other behavioral issues that cannot be controlled by an experiment and can affect the formats differently. Revenue equivalence in the standard symmetric independent-private-values environment has not been reliably confirmed or refuted for this reason (see Kagel, 1995).
} 
partition) of a given format sequentially, using an (extended) dual market technique. More specifically, in any given round, bidders were initially assigned valuations drawn from the uniform distribution over integers ranging from 0 to 100 , and these same valuation profiles were kept throughout that round. Keeping the same valuations while changing the information each bidder has about their rivals enables us to isolate the effect of the rival information, thus preserving the "purity of the ceteris paribus presumption" (see Kagel, 1995). Hence, the (extended) dual market technique makes the testing of our comparative static hypotheses more effective. To maintain the assumed informational structure, bidders were informed of the outcome of all three auctions only at the end of the round, when all three auctions were concluded.

The bidders' identities were unknown to all other bidders to prevent repeated-game effects. The winning bid, the price, and the winner's profit were posted at the end of each round for all three auctions. The valuations assigned to bidders as well as their bids were in discrete integer (or token) units ranging from 1 to 100 with no ceiling on a possible bid. A single token was exchanged for 8 cents, meaning that a subject could earn at most 8 dollars in a given auction game, and 24 dollars in any session. A copy of the instructions can be obtained from the authors. ${ }^{14}$

Since each of the 30 rounds contained 3 auctions and 5 distinct groups, each session included 150 auctions of each of the three types. We ran two sessions for each of the first- and second-price auctions, thus we obtained 300 observations for each partition of first-price and second-price auctions.

\section{Results}

We now present the results of our experiment. We first examine the bidding behavior in the first and second price auctions, and then move on to the revenue and surplus in these formats.

\subsection{Bidding behavior in the first-price auction}

We begin with the most general prediction, FPBL3. Table 1 reports the correlation coefficients between group leaders' bids and their valuations and that between the leaders' bids and their group followers' valuations. It confirms the hypotheses that the correlation between a leaders' bids and followers' valuations rises from Auction 1 (0.38) to Auction 2 (0.57). Note also that in Auction 3, the correlation between the leader's bid and valuation (0.59) is less than the correlation between the leader's bid and the follower's valuation (0.86), as hypothesized in FPBL3.

Table 1

Correlations in the first-price auction

\begin{tabular}{lll}
\hline & Bet. leader's bid and valuation & Bet. leader's bid and follower's valuation \\
\hline${\text { Auction } 1^{\mathrm{a}}}_{\text {Auction 2 }}$ & $0.85(1)$ & $0.38(0.44)$ \\
Auction 3 & $0.82(0.93)$ & $0.57(0.66)$ \\
\hline
\end{tabular}

Note. Numbers in parentheses are the theoretical predictions based on the realized valuations of the experiments.

a Here, leader and follower are as defined in Auction 2.

14 See http://econ.ucsd.edu/ jandreon/, http://www.columbia.edu/ yc2271/, or http://eclass.yonsei.ac.kr/jikimdir/ to download the instructions. 
Next, Table 2 presents the results of the regression equations discussed in FPBL1:

$$
b_{i}^{a}=\max \left\{B_{1}^{a} v_{\ell}, B_{2}^{a} v_{f}\right\}+\varepsilon_{i}^{a}
$$

for Auction $a=1,2,3$. We assume that error terms, $\varepsilon_{i}^{a}$, are independent across bidders and rounds. One possible interpretation of the errors is that they represent random mistakes in calculating the optimal bids. We employed the non-linear least squares method based on (4). The coefficients estimated show how the subjects adjust their bids in response to the information gained about their rivals' types. Overall, the estimated coefficients closely track the theoretical predictions in FPBL1. In particular, the coefficients on the followers' valuations, $B_{2}^{2}$ and $B_{2}^{3}$, are almost exactly 1 , which is strikingly consistent with Bertrand behavior. ${ }^{15}$ (See also Table 3.) The coefficients on own valuations, $B_{1}^{1} \approx 0.79$ and $B_{1}^{2} \approx 0.70$, are greater than their predictions, $3 / 4$ and $2 / 3$, by about 0.04 . The overbidding, while small in average magnitude, is significant at $p \leqslant 0.001{ }^{16}$ As mentioned in Remark 1 , this pattern of overbidding-namely that overbidding is captured only in the coefficients $B_{1}^{1}$ and $B_{1}^{2}$-is consistent with the presence of bidder risk aversion. ${ }^{17}$ More importantly, the decrease in the coefficient on the bidder's own valuation when shifting from Auction 1 to Auction 2 confirms that the bidders shade more when they realize

Table 2

Regression results for the first-price auction

\begin{tabular}{|c|c|c|c|c|c|c|}
\hline & Coef. & Std. Err. & $t$ & $P>|t|$ & \multicolumn{2}{|c|}{ [95\% Conf. Interval] } \\
\hline \multicolumn{7}{|c|}{ Estimated with all Auction 1 bids } \\
\hline$B_{1}^{1}$ & .800 & .005 & 167.44 & 0.000 & .790 & .809 \\
\hline \multicolumn{7}{|c|}{ Estimated with Auction 1 bids by leaders in Auction 2} \\
\hline$B_{1}^{1}$ & .791 & .007 & 118.82 & 0.000 & .778 & .804 \\
\hline \multicolumn{7}{|c|}{ Estimated with the leaders' bids in Auction 2} \\
\hline$B_{1}^{2}$ & .704 & .008 & 92.29 & 0.000 & .689 & .719 \\
\hline$B_{2}^{2}$ & 1.004 & .014 & 72.32 & 0.000 & .977 & 1.031 \\
\hline \multicolumn{7}{|c|}{ Estimated with the leaders' bids in Auction 3} \\
\hline$B_{1}^{3}$ & .145 & 1.32 & 1.09 & 0.276 & -.116 & .405 \\
\hline$B_{2}^{3}$ & .993 & .011 & 93.57 & 0.000 & .972 & 1.013 \\
\hline
\end{tabular}

Table 3

Bid in Auction 3 of the first-price auction

\begin{tabular}{ll}
\hline & Frequency $(\%)$ \\
\hline$b_{1}=v_{2}$ or $v_{2}+1$ & 61.0 \\
$b_{1}>v_{2}+1$ & 27.0 \\
$b_{1}<v_{2}$ & 12.0 \\
$b_{2}=v_{2}$ or $v_{2}-1$ & 48.3 \\
$b_{2}>v_{2}$ & 8.3 \\
$b_{2}<v_{2}-1$ & 43.3 \\
\hline
\end{tabular}

Note. $b_{1}$ and $v_{1}$ denote a leader's bid and valuation, respectively, while $b_{2}$ and $v_{2}$ denote a follower's bid and valuation, respectively.

\footnotetext{
15 Neither coefficient is significantly different from 1 , with $t=0.30$ and $t=0.70$ for $B_{2}^{2}$ and $B_{2}^{3}$ respectively.

16 For $B_{1}^{1}$, we find $t=6.16$, and for $B_{1}^{2}$, we find $t=4.920$. Both $t$-tests are significant beyond the 0.001 level.

17 Assuming CRRA utility, $u(\pi)=\pi^{r}$, Cox et al. (1988) have shown that the bid coefficients should be $B_{1}(v, n)=$ $(n-1) v /(n-r)$, where $n$ is 4 in Auction 1 and 3 in Auction 2. Our estimates would be consistent with $r \approx 0.2$.
} 
Table 4

Leader's bid in Auction 2 of the first-price auction

\begin{tabular}{|c|c|c|}
\hline & Frequency $(\%)$ & \\
\hline & \multicolumn{2}{|c|}{ Overall } \\
\hline$v_{2}<b_{1}^{\prime}<v_{1}$ & \multicolumn{2}{|c|}{88.9} \\
\hline$b_{1}^{\prime}<v_{2}$ & \multicolumn{2}{|c|}{2.5} \\
\hline$b_{1}^{\prime}>v_{1}$ & \multicolumn{2}{|c|}{8.8} \\
\hline & Conditional on $b_{1}>v_{2}+1$ & Conditional on $b_{1} \leqslant v_{2}+1$ \\
\hline$b_{1}^{\prime} \geqslant b_{1}$ & 36.8 & \\
\hline$v_{2}+1<b_{1}^{\prime}<b_{1}$ & 49.2 & \\
\hline$b_{1}^{\prime}=v_{2}$ or $v_{2}+1$ & 12.5 & \\
\hline$b_{1}^{\prime}<v_{2}$ & 1.5 & \\
\hline$b_{1}^{\prime}>v_{2}+1$ & & 13.3 \\
\hline$b_{1}^{\prime}=v_{2}$ or $v_{2}+1$ & & 53.8 \\
\hline$b_{1}^{\prime}<v_{2}$ & & 32.9 \\
\hline
\end{tabular}

Note. $b_{1}^{\prime}$ denotes a leader's bid in Auction 2 while $b_{1}$ denotes his bid in Auction 1 , and $v_{1}$ and $v_{2}$ denote his valuation and his follower's valuation, respectively.

that within-group rivals have sufficiently low valuations, which is again consistent with the way bidders were hypothesized to react to the knowledge of their rivals' types. Hence, these results favor a theory of risk aversion over joy-of-winning bias. ${ }^{18}$

Table 4 further tests the implications on the leader's bidding behavior in the first-price auction. The leaders are shown to bid between their valuations and those of the followers $89 \%$ of the time. The leaders' adjustment of bids to the rivals' valuations hypothesized in (2) and (3) also receives some support. When realizing that their Auction 1 bids were higher than their follower's valuations (i.e., $b_{1}>v_{2}+1$ ), the leaders lowered their Auction 2 bids $63 \%$ of the time-to lower unconstrained bids for $49.2 \%$ of the time and to followers' valuations for $12.5 \%$ of the time. In the case that leaders' Auction 1 bids were less than their followers' valuations (i.e., $b_{1} \leqslant v_{2}+1$ ), a significant portion (about 54\%) of leaders raised their bids up to the followers' valuations, as hypothesized in (3).

Turning to Auction 3, Table 3 largely supports the hypothesized Bertrand behavior, from both leaders and followers. Specifically, about 61 percent of the leaders' bids match the equilibrium predictions. ${ }^{19}$ About 48 percent of the followers' bids match the Bertrand predictions in the strong sense that they are equal to or a unit below their valuations. ${ }^{20}$ This is remarkable given that followers' equilibrium responses/best responses are not unique in a Bertrand game. As mentioned in Section 2.2, any bids below or equal to ones' valuations are optimal and can be equilibrium behavior. In light of this, about 92 percent of all followers' bids are consistent with equilibrium/optimizing behavior.

\subsection{Bidding behavior in the second-price auction}

Table 5 presents the distribution of bids that match the dominance hypothesis and those displaying deviations, and shows the patterns of the deviations. About 77 percent of total bids in

\footnotetext{
18 This concurs with Goeree et al. (2002) who jointly test CRRA preferences and joy-of-winning, and find no significant joy-of-winning bias.

19 Of the leaders' bids consistent with the Bertrand behavior, 20 percent of the bids equal the second highest values and the others are a unit above them.

20 Of such bids by the followers, about half of them equal the followers' valuations and the other half a unit below them.
} 
Table 5

Underbids and overbids in the second-price auction

\begin{tabular}{|c|c|c|c|}
\hline & \multicolumn{3}{|c|}{ Frequency $(\%)$} \\
\hline & Auction 1 & Auction 2 & Auction 3 \\
\hline Truthful bid & 77.3 & 66.4 & 58.4 \\
\hline Truthful bid in last 10 rounds & 85.5 & 72.3 & 62.5 \\
\hline Truthful bid by leader & $\mathrm{n} / \mathrm{a}$ & 78.7 & 67.2 \\
\hline Truthful bid by leader in last 10 rounds & $\mathrm{n} / \mathrm{a}$ & 88.2 & 72.0 \\
\hline Truthful bid by non-leader & $\mathrm{n} / \mathrm{a}$ & 53.9 & 55.3 \\
\hline Truthful bid by non-leader in last 10 rounds & $\mathrm{n} / \mathrm{a}$ & 55.6 & 59.0 \\
\hline Underbid & $8.8(18.1)$ & $11.9(26.0)$ & $16.5(29.8)$ \\
\hline Underbid in last 10 rounds & $2.5(18.8)$ & $5.5(30.9)$ & $12.3(32.0)$ \\
\hline Overbid & $14.5(15.2)$ & $21.7(19.9)$ & $25.1(16.6)$ \\
\hline Overbid in last 10 rounds & $12.0(7.0)$ & $22.0(17.1)$ & $25.3(26.1)$ \\
\hline Overbid by leader in Auction 2 & $14.2(12.7)$ & $11.9(11.2)$ & $23.1(21.9)$ \\
\hline Overbid by non-leader in Auction 2 & $13.8(17.8)$ & $31.6(23.3)^{\mathrm{a}}$ & $27.1(30.8)$ \\
\hline Overbid by leader in Auction 3 & $18.0(12.0)$ & $13.5(11.0)$ & $18.0(30.9)$ \\
\hline Overbid by non-leader in Auction 3 & $12.6(16.8)$ & $24.5(21.6)$ & $27.6(25.9)^{b}$ \\
\hline Underbid by leader in Auction 2 & $8.4(19.0)$ & $9.4(19.3)$ & $15.2(28.8)$ \\
\hline Underbid by non-leader in Auction 2 & $9.1(17.2)$ & $14.5(30.4)$ & $17.8(30.7)$ \\
\hline Underbid by leader in Auction 3 & $8.0(19.3)$ & $9.6(22.0)$ & $14.8(21.0)$ \\
\hline Underbid by non-leader in Auction 3 & $9.0(17.7)$ & $12.7(8.8)$ & $17.1(32.5)$ \\
\hline
\end{tabular}

Note. Numbers in parentheses are the expected amounts of overbid or underbid conditional on the corresponding events.

a Among the bids falling into this category, about $22 \%$ are greater than or equal to the leaders' valuations.

b Among the bids falling into this category, about $11 \%$ are greater than or equal to the leaders' valuations.

Auction 1 are consistent with truthful bidding. The proportion of truthful bids falls to $66 \%$ in Auction 2 and to 58\% in Auction 3, showing that violations of the dominance hypothesis are more pronounced when information about more rivals is learned. At the same time, the proportion of truthful bids remains high among leaders in Auctions 2 and 3 (78.7 and 67.2\%, respectively), particularly in the last 10 rounds ( 88.2 and $72.0 \%$, respectively). Of nontruthful bids, there are more overbids than underbids, but both types of deviations are more pronounced as we shift from Auction 1 to Auction 2 and to Auction 3. The underbids dissipate significantly in the last 10 rounds, whereas the overbids do not show any systematic dissipation in the later rounds. The dissipation of the underbids suggests that a large portion of the underbids may have been caused by mistakes in strategic considerations, which are corrected as one gains more experience. Meanwhile, the persistence of overbidding warrants careful analysis.

Toward this end, we examine the pattern of overbidding, paying special attention to when a bidder is more likely to overbid and how much he/she overbids relative to rival bidders' valuations. Table 5 shows that an increase in overbids is most pronounced when the followers learn the leaders' valuations. The non-leaders' overbids increase by about $18 \%$ going from Auction 1 $(13.8 \%)$ to $2(31.6 \%)$. Also, the overbids by those who are leaders in Auction 2 but not in Auction 3 increase by about $18 \%$ going from Auction $2(10.2 \%)$ to Auction 3 (28.5\%). While the modest overbidding found in Auction 1 may be explainable by strategic mistakes, the dramatic increase in overbidding among the non-leaders in Auctions 2 and 3 appears to indicate the presence of spite, since raising bids to hurt the winner becomes less risky when a follower learns of 
his group leader's valuation (and thus his likely bid). ${ }^{21}$ The presence of the spite motive is also revealed in a questionnaire administered to the subjects after the experiment. In the questionnaire, subjects were asked whether they ever bid more than their valuations. If they had overbid, then they were asked, in an open-ended question, to explain why. Examining the answers reveals that out of 40 participants, 24 report having overbid and half of them volunteered that they did so to reduce the earnings of winners. Some participants even reported that they only overbid if they are in a 'losing situation.' This is remarkable since our questionnaire never suggested any reasons to subjects.

The bidding pattern in a second-price auction can also be learned from reduced-form regressions of bids in Auction 2 and 3:

$$
b_{i}^{a}=A+B_{1}^{a} \cdot v_{i}+B_{2}^{a} \cdot v_{m(i)},
$$

where $b_{i}^{a}$ is bidder $i$ 's bid in Auction $a=2,3, v_{i}$ is his valuation, and $v_{m(i)}$ is the highest valuation in his group except for his own. The estimation results are reported in Table $6 .{ }^{22}$ For the leaders, the estimate of the own valuation coefficient $B_{1}^{a}$ is close to, and not significantly different from, 1 in both Auction 2 and Auction 3, but the coefficient on the highest rival's valuation $B_{2}^{a}$ is close to zero and insignificant for both auctions, as are the constant terms $A .{ }^{23}$ This indicates that the leaders bid close to their valuations and do not adjust their bids to the rivals' valuations. Hence, the dominance hypothesis receives compelling support for the case of leaders. By contrast, the followers' bids show more sensitivity to the highest rivals' bids ( $B_{2}^{2}$ is 0.07 and marginally significant, while $B_{2}^{3}$ is 0.20 and significant). In particular, the high coefficient on $v_{m}(i)$ in Auction 3 indicates that a bidder is willing to raise his bid most significantly relative to the leader's valuation when safe with the knowledge that he will not be winning and his bid will set the selling price. ${ }^{24}$ Meanwhile, the second and third followers' bids in Auction 3 do not exhibit any appreciable sensitivity to the leaders' valuations. ${ }^{25}$ This lack of sensitivity is consistent with the fact that their bids, unlike the followers', are unlikely to set the prices winners will pay. From this perspective, the overbids made by the second and third followers may be best explained as strategic mistakes.

The distribution of overbids among followers can yield further insights about the various explanations for overbidding. Table 7 and Fig. 1 report the frequency of overbids, organizing the overbids by how close the follower's bid is to the leaders valuation. Notice that $90 \%$ of the overbids do not exceed the group leader's valuation. This all but rules out "joy of winning" as a major cause of overbidding, since at most $10 \%$ of overbids are explainable by that motive. More telling of the likely cause of overbidding is the large spike just below the leaders'

\footnotetext{
21 Bidders with low valuations are unlikely to win, so they may be more likely to commit strategic errors. Since these bidders are also more likely to be non-leaders, "errors" theory could explain an increase in the frequency of overbids by non-leaders in Auctions 2 and 3, relative to the overall frequency of overbids in Auction 1. Notice, however, that the increase in overbids reported in Table 5 restricts attention to the same set of bidders, with their valuations held fixed. Hence, the selection bias cannot explain the increase.

22 We ran a supplementary regression with a random-effects model to account for the individual characteristics without finding the regression results much different from those of OLS regressions.

23 Testing the null hypothesis $B_{1}^{a}=1$, we have for leaders $B_{1}^{2}=0.98, t=0.83$ and $B_{1}^{3}=0.83, t=1.70$ while for followers we have $B_{1}^{2}=0.70, t=7.05$ and $B_{1}^{3}=0.68, t=4.10$.

24 In Auction 2, a follower knows that he will not be winning but he does not know his bid will set the selling price, due to the uncertainty about the types of the other group bidders.

25 The estimates of $B_{2}^{3}$ for these bidders are 0.096 and 0.072 , respectively, and the hypothesis that this values are zero cannot be rejected at $95 \%$ probability.
} 
Table 6

Regression results for the second-price auction

\begin{tabular}{|c|c|c|c|c|c|c|}
\hline & Coef. & Std. Err. & $t$ & $P>|t|$ & \multicolumn{2}{|c|}{ [95\% Conf. Interval] } \\
\hline \multicolumn{7}{|c|}{ Estimated with the leaders' bids in Auction 2} \\
\hline$A$ & .383 & 1.245 & 0.31 & 0.758 & -2.061 & 2.827 \\
\hline$B_{1}^{2}$ & .983 & .020 & 48.46 & 0.000 & .943 & 1.023 \\
\hline$B_{2}^{2}$ & .008 & .022 & 0.37 & 0.710 & -.035 & .051 \\
\hline \multicolumn{7}{|c|}{ Estimated with the followers' bids in Auction 2} \\
\hline$A$ & 7.563 & 2.530 & 2.99 & 0.003 & 2.594 & 12.532 \\
\hline$B_{1}^{2}$ & .696 & .0443 & 15.72 & 0.000 & .609 & .783 \\
\hline$B_{2}^{2}$ & .0762 & .0409 & 1.86 & 0.063 & -.004 & .157 \\
\hline \multicolumn{7}{|c|}{ Estimated with the leaders' bids in Auction 3} \\
\hline$A$ & 10.103 & 6.480 & 1.56 & 0.120 & -2.650 & 22.857 \\
\hline$B_{1}^{3}$ & 0.834 & 0.100 & 8.31 & 0.000 & 0.636 & 1.031 \\
\hline$B_{2}^{3}$ & 0.092 & 0.089 & 1.04 & 0.301 & -0.083 & 0.266 \\
\hline \multicolumn{7}{|c|}{ Estimated with the followers' bids in Auction 3} \\
\hline$A$ & 0.139 & 5.675 & 0.02 & 0.981 & -11.023 & 11.307 \\
\hline$B_{1}^{3}$ & 0.675 & 0.078 & 8.70 & 0.000 & .522 & 0.828 \\
\hline$B_{2}^{3}$ & 0.198 & 0.088 & 2.26 & 0.025 & 0.025 & 0.371 \\
\hline \multicolumn{7}{|c|}{ Estimated with the second followers' bids in Auction 3} \\
\hline$A$ & 4.783 & 5.958 & 0.80 & 0.423 & -6.942 & 16.508 \\
\hline$B_{1}^{3}$ & 0.654 & 0.077 & 8.50 & 0.000 & 0.503 & 0.808 \\
\hline$B_{2}^{3}$ & 0.096 & 0.709 & 1.22 & 0.225 & -0.059 & 0.252 \\
\hline \multicolumn{7}{|c|}{ Estimated with the third followers' bids in Auction 3} \\
\hline$A$ & 7.611 & 6.081 & 1.25 & 0.212 & -4.357 & 19.579 \\
\hline$B_{1}^{3}$ & 0.751 & 0.084 & 8.89 & 0.000 & 0.585 & 0.917 \\
\hline$B_{2}^{3}$ & 0.072 & 0.077 & 0.94 & 0.347 & -0.079 & 0.224 \\
\hline
\end{tabular}

valuations. Specifically, $19 \%$ of overbids are 1 unit below the leaders' valuations and $17 \%$ are between 2 and 5 units below the leaders' valuations. This concentration of overbids just below leaders' valuations are suggestive of the intention by followers to limit the surplus accruing to the leaders.

The alternative motives are, of course, not mutually exclusive. The same subject may adopt different motives depending on the circumstances. In this regard, the individual distribution of overbids in Table 7 gives a richer portrayal of behavioral patterns and motives. In particular, the behavior of several bidders (subjects \#1, 12, 13, 16, 17, 13, 26, 27, 28, 29, 40) appears consistent with spite; overbids by a few bidders (subjects \#12, 14, 15, 21, and 37) appears motivated by the joy of winning; and the more disbursed distributions of overbids among a few bidders (subjects \#6, 18, 20, 31, 39, and 39) appears consistent with the errors hypothesis.

\subsection{Revenue and surplus performances}

We now turn to the revenue and surplus performances of the two auctions. While the bidding behavior results reported above yield an immediate implications for revenues, their implications for allocative efficiencies are not clear. We begin with Table 8 which presents the theoretical 
Table 7

Distribution of overbids by followers in Auctions 2 and 3

\begin{tabular}{|c|c|c|c|c|c|c|c|c|}
\hline \multirow[t]{2}{*}{ Bidder } & \multirow{2}{*}{$\begin{array}{l}\text { Frequency of } \\
\text { overbid conditional } \\
\text { on being } \\
\text { a follower }(\%)\end{array}$} & \multicolumn{7}{|c|}{$\begin{array}{l}\text { Frequency of } D:=\text { Follower's bid minus leader's valuation } \\
\text { conditional on the follower overbidding }(\%)\end{array}$} \\
\hline & & $D \leqslant-16$ & $\begin{array}{l}D=-15 \\
\text { to }-6\end{array}$ & $\begin{array}{l}D=-5 \\
\text { to }-2\end{array}$ & $D=-1$ & $D=0$ & $\begin{array}{l}D=1 \\
\text { or } 2\end{array}$ & $D \geqslant 3$ \\
\hline 1 & 48.1 & 15.4 & 30.8 & 7.7 & 30.8 & 15.4 & 0.0 & 0.0 \\
\hline 2 & 8.3 & 100.0 & 0.0 & 0.0 & 0.0 & 0.0 & 0.0 & 0.0 \\
\hline 3 & 38.9 & 0.0 & 14.3 & 71.4 & 14.3 & 0.0 & 0.0 & 0.0 \\
\hline 4 & 0.0 & $\mathrm{n} / \mathrm{a}$ & $\mathrm{n} / \mathrm{a}$ & $\mathrm{n} / \mathrm{a}$ & $\mathrm{n} / \mathrm{a}$ & $\mathrm{n} / \mathrm{a}$ & $\mathrm{n} / \mathrm{a}$ & $\mathrm{n} / \mathrm{a}$ \\
\hline 5 & 47.8 & 36.4 & 54.5 & 9.1 & 0.0 & 0.0 & 0.0 & 0.0 \\
\hline 6 & 91.7 & 9.1 & 13.6 & 31.8 & 9.1 & 9.1 & 9.1 & 18.2 \\
\hline 7 & 11.1 & 100.0 & 0.0 & 0.0 & 0.0 & 0.0 & 0.0 & 0.0 \\
\hline 8 & 4.8 & 100.0 & 0.0 & 0.0 & 0.0 & 0.0 & 0.0 & 0.0 \\
\hline 9 & 28.6 & 66.7 & 0.0 & 33.3 & 0.0 & 0.0 & 0.0 & 0.0 \\
\hline 10 & 0.0 & $\mathrm{n} / \mathrm{a}$ & $\mathrm{n} / \mathrm{a}$ & $\mathrm{n} / \mathrm{a}$ & $\mathrm{n} / \mathrm{a}$ & $\mathrm{n} / \mathrm{a}$ & $\mathrm{n} / \mathrm{a}$ & $\mathrm{n} / \mathrm{a}$ \\
\hline 11 & 0.0 & $\mathrm{n} / \mathrm{a}$ & $\mathrm{n} / \mathrm{a}$ & $\mathrm{n} / \mathrm{a}$ & $\mathrm{n} / \mathrm{a}$ & $\mathrm{n} / \mathrm{a}$ & $\mathrm{n} / \mathrm{a}$ & $\mathrm{n} / \mathrm{a}$ \\
\hline 12 & 15.0 & 0.0 & 0.0 & 0.0 & 33.3 & 0.0 & 66.7 & 0.0 \\
\hline 13 & 9.5 & 50.0 & 0.0 & 0.0 & 0.0 & 50.0 & 0.0 & 0.0 \\
\hline 14 & 4.2 & 0.0 & 0.0 & 0.0 & 0.0 & 0.0 & 0.0 & 100.0 \\
\hline 15 & 15.4 & 0.0 & 25.0 & 0.0 & 0.0 & 0.0 & 25.0 & 50.0 \\
\hline 16 & 61.1 & 27.3 & 9.1 & 9.1 & 27.3 & 9.1 & 9.1 & 9.1 \\
\hline 17 & 45.8 & 27.3 & 18.2 & 45.5 & 9.1 & 0.0 & 0.0 & 0.0 \\
\hline 18 & 56.5 & 38.5 & 15.4 & 15.4 & 7.7 & 15.4 & 7.7 & 0.0 \\
\hline 19 & 61.9 & 53.8 & 38.5 & 0.0 & 0.0 & 0.0 & 7.7 & 0.0 \\
\hline 20 & 57.1 & 50.0 & 33.3 & 16.7 & 0.0 & 0.0 & 0.0 & 0.0 \\
\hline 21 & 11.1 & 0.0 & 0.0 & 50.0 & 0.0 & 0.0 & 0.0 & 50.0 \\
\hline 22 & 0.0 & $\mathrm{n} / \mathrm{a}$ & $\mathrm{n} / \mathrm{a}$ & $\mathrm{n} / \mathrm{a}$ & $\mathrm{n} / \mathrm{a}$ & $\mathrm{n} / \mathrm{a}$ & $\mathrm{n} / \mathrm{a}$ & $\mathrm{n} / \mathrm{a}$ \\
\hline 23 & 13.0 & 33.3 & 33.3 & 0.0 & 33.3 & 0.0 & 0.0 & 0.0 \\
\hline 24 & 0.0 & $\mathrm{n} / \mathrm{a}$ & $\mathrm{n} / \mathrm{a}$ & $\mathrm{n} / \mathrm{a}$ & $\mathrm{n} / \mathrm{a}$ & $\mathrm{n} / \mathrm{a}$ & $\mathrm{n} / \mathrm{a}$ & $\mathrm{n} / \mathrm{a}$ \\
\hline 25 & 0.0 & $\mathrm{n} / \mathrm{a}$ & $\mathrm{n} / \mathrm{a}$ & $\mathrm{n} / \mathrm{a}$ & $\mathrm{n} / \mathrm{a}$ & $\mathrm{n} / \mathrm{a}$ & $\mathrm{n} / \mathrm{a}$ & $\mathrm{n} / \mathrm{a}$ \\
\hline 26 & 30.8 & 0.0 & 12.5 & 12.5 & 62.5 & 12.5 & 0.0 & 0.0 \\
\hline 27 & 61.9 & 7.7 & 7.7 & 23.1 & 30.8 & 30.8 & 0.0 & 0.0 \\
\hline 28 & 69.6 & 0.0 & 0.0 & 0.0 & 93.8 & 0.0 & 6.3 & 0.0 \\
\hline 29 & 4.8 & 0.0 & 0.0 & 0.0 & 100.0 & 0.0 & 0.0 & 0.0 \\
\hline 30 & 0.0 & $\mathrm{n} / \mathrm{a}$ & $\mathrm{n} / \mathrm{a}$ & $\mathrm{n} / \mathrm{a}$ & $\mathrm{n} / \mathrm{a}$ & $\mathrm{n} / \mathrm{a}$ & $\mathrm{n} / \mathrm{a}$ & $\mathrm{n} / \mathrm{a}$ \\
\hline 31 & 44.4 & 41.7 & 16.7 & 25.0 & 0.0 & 0.0 & 0.0 & 16.7 \\
\hline 32 & 0.0 & $\mathrm{n} / \mathrm{a}$ & $\mathrm{n} / \mathrm{a}$ & $\mathrm{n} / \mathrm{a}$ & $\mathrm{n} / \mathrm{a}$ & $\mathrm{n} / \mathrm{a}$ & $\mathrm{n} / \mathrm{a}$ & $\mathrm{n} / \mathrm{a}$ \\
\hline 33 & 40.0 & 20.0 & 70.0 & 10.0 & 0.0 & 0.0 & 0.0 & 0.0 \\
\hline 34 & 65.0 & 23.1 & 53.8 & 23.1 & 0.0 & 0.0 & 0.0 & 0.0 \\
\hline 35 & 5.0 & 100.0 & 0.0 & 0.0 & 0.0 & 0.0 & 0.0 & 0.0 \\
\hline 36 & 90.5 & 5.3 & 26.3 & 15.8 & 15.8 & 15.8 & 0.0 & 21.1 \\
\hline 37 & 11.1 & 0.0 & 0.0 & 0.0 & 0.0 & 0.0 & 0.0 & 100.0 \\
\hline 38 & 60.9 & 35.7 & 14.3 & 0.0 & 0.0 & 50.0 & 0.0 & 0.0 \\
\hline 39 & 37.5 & 16.7 & 16.7 & 50.0 & 16.7 & 0.0 & 0.0 & 0.0 \\
\hline 40 & 68.2 & 6.7 & 13.3 & 13.3 & 53.3 & 6.7 & 6.7 & 0.0 \\
\hline Overall & 30.3 & 23.4 & 21.6 & 17.1 & 19.0 & 8.9 & 3.7 & 6.3 \\
\hline
\end{tabular}

predictions for revenue and surplus based on the actual valuation profiles as realized in the experiment. ${ }^{26}$ Note that the predicted effects of the rival information on the revenue and surplus in

26 In a Bertrand situation arising in Auction 2 and Auction 3, there are two pure strategy equilibria where a leader's bid is either the second highest value or one unit above it. We presume the two equilibrium prices to be equally probable, thus taking the second highest value plus a half token unit as our theoretical prediction. 


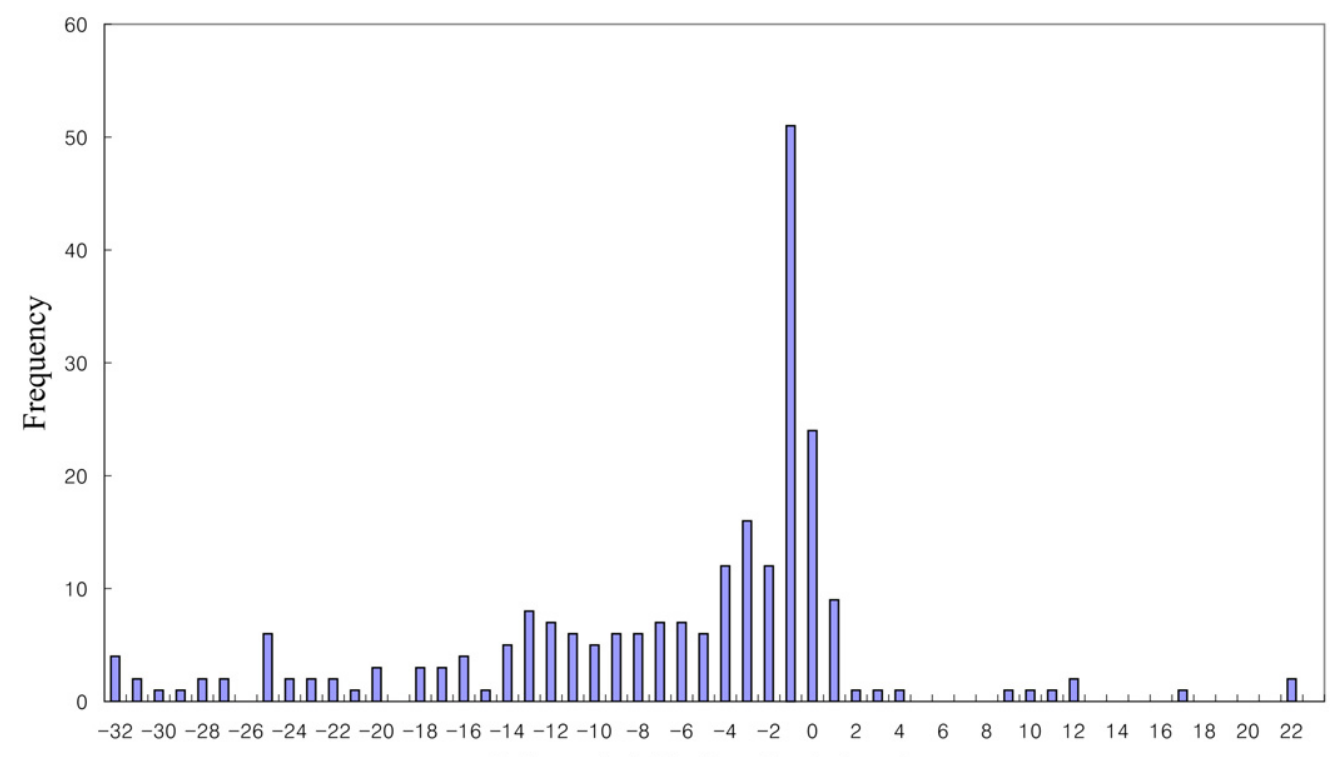

Follower's bid minus leader's value

Fig. 1. Frequency of follower's bid minus leader's valuation conditional on the follower overbidding.

Table 8

Theoretical values of revenue and surplus in the first-price auction

\begin{tabular}{llccc}
\hline Revenue & Surplus & $\begin{array}{l}\text { Frequency of } \\
\text { inefficient } \\
\text { allocation }(\%)\end{array}$ & $\begin{array}{c}\text { Average ratio } \\
\text { between winner's \& } \\
\text { highest values }(\%)\end{array}$ \\
\hline Auction 1 & 58.26 & 77.68 & 0.0 & 100 \\
Auction 2 & 56.72 & 76.75 & 10.6 & 99.1 \\
Auction 3 & $56.99^{\mathrm{a}}$ & 77.68 & 0.0 & 100 \\
\hline
\end{tabular}

a This number is the average of (follower's valuation plus 0.5 ).

both auctions are small in magnitude relative to the natural variance found in the data. Therefore, we would not expect effects to be statistically significant.

Table 9 reports the actual revenue and surplus from the first-price auctions under different information structures. The revenue results track the bidding behavior reported earlier. Namely, the revenue difference (of about 3.3 in token units) between Auction 1 and Auction 2 is in the right direction, consistent with FPRS, but more than doubles the amount predicted by the theory (about 1.5). The revenue ranking between Auctions 2 and 3 is contrary to the prediction, although not significant. Again risk aversion accounts for this deviation from predictions. As noted in Remark 1, risk aversion causes bidders to be more aggressive when facing more uncertainties, which could explain the amplified revenue ranking between Auctions 1 and 2 and the reversal of the predicted ranking between Auction 2 and 3. Total surplus should be less susceptible to the risk aversion effect if the degree of risk aversion is similar across the bidders. Indeed, the surplus rankings across different information structures are consistent with FPRS, exhibiting the non-monotonicity, though not significantly.

Table 10 reports the revenue and surplus observed from our second-price auction experiment. Their theoretical predictions are the same as those in Auctions 1 and 3 of a first-price auction 
Table 9

Realized values of revenue and surplus in the first-price auction

\begin{tabular}{lcccc}
\hline & Revenue & Surplus & $\begin{array}{l}\text { Frequency of } \\
\text { inefficient } \\
\text { allocation (\%) }\end{array}$ & $\begin{array}{c}\text { Average ratio } \\
\text { between winner's \& } \\
\text { highest values }(\%)\end{array}$ \\
\hline Auction 1 & 63.31 & 74.92 & 21.5 & 96.5 \\
Auction 2 & 60.00 & 74.58 & 21.9 & 96.0 \\
Auction 3 & 58.78 & 74.87 & 17.4 & 96.2 \\
$\quad$ Difference & $3.31^{\mathrm{a}}$ & $0.34^{\mathrm{b}}$ & & \\
Auc. 1 - Auc. 2 & $1.22^{\mathrm{b}}$ & $-0.29^{\mathrm{b}}$ & & \\
Auc. 2 - Auc. 3 & $4.53^{\mathrm{a}}$ & $0.05^{\mathrm{b}}$ & & \\
Auc. 1 - Auc. 3 & & & & \\
\hline
\end{tabular}

a The null hypothesis that this difference is zero is rejected at $1 \%$ level in favor of the alternative hypothesis that it is positive.

b The null hypothesis that this difference is zero is not rejected at $10 \%$ level.

Table 10

Revenue and Surplus in the second-price auction

\begin{tabular}{lcccc}
\hline & Revenue & Surplus & $\begin{array}{l}\text { Frequency of } \\
\text { inefficient } \\
\text { allocation }(\%)\end{array}$ & $\begin{array}{c}\text { Average ratio } \\
\text { between winner's \& } \\
\text { highest values }(\%)\end{array}$ \\
\hline Auction 1 & 56.3 & 76.37 & 9.6 & 97.9 \\
Auction 2 & 58.6 & 75.11 & 11.9 & 96.6 \\
Auction 3 & 60.7 & 74.16 & 14.5 & 95.3 \\
Difference & $2.27^{\mathrm{a}}$ & $1.26^{\mathrm{b}}$ & & \\
Auc. 1 - Auc. 2 & $-2.1^{\mathrm{a}}$ & $0.95^{\mathrm{c}}$ & & \\
Auc. 2 - Auc. 3 & $-4.37^{\mathrm{a}}$ & $2.21^{\mathrm{d}}$ & & \\
Auc. 1 - Auc. 3 & & & & \\
\hline
\end{tabular}

Note. Theoretical values of surplus and revenue are 77.68 and 56.49, respectively.

a The hypothesis that this difference is zero is rejected at $1 \%$ level in favor of the alternative hypothesis that it is negative.

$\mathrm{b}$ The hypothesis that this difference is zero is not rejected at $1 \%$ level but rejected at $5 \%$ in favor of the alternative hypothesis that it is positive.

$\mathrm{c}$ The hypothesis that this difference is zero is not rejected at $10 \%$ level.

$\mathrm{d}$ The hypothesis that this difference is zero is rejected at $1 \%$ level in favor of the alternative hypothesis that it is positive.

(in Table 8). According to SPRS, the revenue and surplus should not depend on the information structure. This hypothesis is rejected for nearly all the binary comparisons, as shown in the Table 10. Indeed, Table 10 shows that revealing information about more rivals to the bidders results in higher revenue and, less significantly, lower surplus. This behavior seems consistent with aforementioned overbidding by the followers, which becomes more pronounced as they gain information about rivals. In a second-price auction, a follower's overbidding raises the selling price (and thus revenue) and this can cause an inefficient allocation if a leader underbids. ${ }^{27}$

27 Note that a defensive action against spiteful opponents is for leader to bid below his valuation (but above the follower's) thus putting spiteful followers at risk. Unfortunately, we have no way of testing this "reciprocal spite" motive in our data. 


\section{Concluding remarks}

We have studied experimentally the effect bidder's information about rivals' types has on bidding behavior in both first- and second-price auctions. The results of the experiment appear to support the hypotheses adapted from KC (2004). In the experiments on the first-price auction, subjects' bidding behavior relative to their valuations as well as their adjustments of bids to the information about their rivals appears to closely match the pattern predicted by theory. In particular, the structural estimation shows that subjects' behavior in a Bertrand setting (in Auctions 2 and 3) approximated the theoretical predictions quite closely, and their bidding in non-Bertrand setting is also consistent with the theory once the risk aversion effect accounted for. Our experiment on second-price auctions also confirmed important elements of the theory. In particular, bidders appeared to largely follow the dominant strategy of bidding their valuations, except when they become convinced of losing an auction and are in a position to influence the selling price. Subjects tended to overbid in the latter setting, which seems consistent with the spite motive theory.

The comparative statics hypotheses provide additional restrictions on the theory that are largely robust to risk aversion and other behavioral motives that some past auction experiments were susceptible to. Thus, our experimental support of the theory appears to provide a more compelling endorsement for the underlying game-theoretic paradigm as a behavioral framework than has been possible with previous auction experiments. Further, the enhanced control on the behavioral issues and risk attitudes could provide a better understanding on the roles they play in auction experiments. In particular, our study adds credibility to the view that risk aversion may have caused subjects to overbid in first-price auctions, and that spiteful feelings are lingering among the followers in second-price auctions.

\section{Acknowledgments}

We are grateful to Phil Haile, John Kagel, Dan Levin, Larry Samuelson, Bill Sandholm, Associate Editor and the referees, for numerous helpful comments, and to the National Science Foundation (SES0137162) for financial support.

\section{Appendix A. Proof of FPBL}

We prove that it is an equilibrium behavior for leaders to employ the bidding function in (1) and for the followers to bid their valuations. Clearly, followers' behavior is optimal, if all other bidders follow the hypothesized strategies. ${ }^{28}$ We now show the optimality of the leaders' strategies. When all others follow the suggested equilibrium strategies, a leader wins only if he outbids the followers in his group and the leaders of the $k-1$ other groups. Hence, if a group leader bids $b$ that exceeds the valuations of the followers in his group, he will win with probability,

$$
\begin{aligned}
y(b) & :=\operatorname{Prob}\left\{\max \left\{\beta_{\ell}^{m}\left(v_{\ell}\right), v_{f}\right\} \leqslant b\right\}^{k-1} \\
& =\operatorname{Prob}\left\{v_{\ell} \leqslant\left(\beta_{\ell}^{m}\right)^{-1}(b)=\frac{n-m+1}{n-m} b \text { and } v_{f} \leqslant b\right\}^{k-1}
\end{aligned}
$$

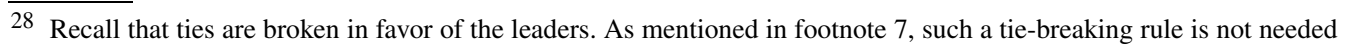
when the valuations are discrete, as is the case with our experiment. 


$$
\begin{aligned}
& =\left\{m F^{m-1}(b)\left(F\left(\frac{n-m+1}{n-m} b\right)-F(b)\right)+F^{m}(b)\right\}^{k-1} \\
& =\left(m b^{m-1} \min \left\{\frac{n-m+1}{n-m} b, 1\right\}-(m-1) b^{m}\right)^{k-1},
\end{aligned}
$$

where $F$ is the cumulative distribution function of the valuation, which is assumed here to be uniform over $[0,1]$. Then, a group leader with valuation $v_{\ell}$ solves

$$
\max _{b \geqslant 0} y(b)\left(v_{\ell}-b\right)
$$

subject to

$$
b \geqslant v_{f} \text {. }
$$

It can be easily verified that $y(b)\left(v_{\ell}-b\right)$ is increasing with $b$ for $b<\frac{n-m}{n-m+1} v_{\ell}$ and decreasing for $b>\frac{n-m}{n-m+1} v_{\ell}$, which implies that $\max \left\{\frac{n-m}{n-m+1} v_{\ell}, v_{f}\right\}$ is optimal for the leader, given that all others follow the hypothesized strategies. We have thus proven that the behavior described in FPBL constitutes a (Bayesian) Nash equilibrium.

\section{References}

Bajari, P., Hortacsu, A., 2004. Are structural estimates of auction models reasonable? Evidence from experimental data. Working paper.

Bergemann, D., Pesendorfer, M., 2003. Information structures in optimal auctions, Mimeo. LSE.

Blume, A., 2003. Bertrand without fudge. Econ. Letters 78, 167-168.

Campo, S., Guerre, E., Perrigne, I., Vuong, Q., 2002. Semi-parametric estimation of first-price auctions with risk averse bidders. Working paper. University of Southern California.

Chen, K.-Y., Plott, C.R., 1998. Nonlinear behavior in sealed bid first-price auctions. Games Econ. Behav. 25 , 34-78.

Cooper, D., Fang, H.-M., 2006. Understanding overbidding in second price auctions: An experimental study. Discussion paper 1557. Cowles Foundation.

Cox, J.C., Smith, V.L., Walker, J.M., 1988. Theory and individual behavior of first-price auctions. J. Risk Uncertainty 1 , 61-99.

Dyer, D., Kagel, J., Levin, D., 1989. Resolving uncertainties about numbers of bidders in independent private values auctions: An experimental analysis. RAND J. Econ. 20, 268-279.

Eso, P., Szentes, B., 2006. Optimal information disclosure in auction: The handicap auction. Mimeo. Northwestern University.

Fang, H.-M., Morris, S., 2006. Multidimensional private value auctions. J. Econ. Theory 126, 1-30.

Goeree, J., Holt, C., Palfrey, T., 2002. Quantal response equilibrium and overbidding in private value auctions. J. Econ. Theory 104, 247-272.

Kagel, J., 1995. Auctions: A survey of experimental research. In: Kagel, J., Roth, A. (Eds.), Handbook of Experimental Economics. Princeton Univ. Press.

Kagel, J., Levin, D., 1993. Independent private value auctions: Bidder behavior in first, second and third-price auctions with varying numbers of bidders. Econ. J. 103, 868-879.

Kagel, J., Harstad, R., Levin, D., 1987. Information impact and allocation rules in auctions with affiliated private values. Econometrica 55 (6), 1275-1304.

Kim, J., Che, Y.-K. (KC), 2004. Asymmetric information about rivals' types in standard auctions. Games Econ. Behav. 46, 383-397.

Morgan, J., Steiglitz, K., Reis, G., 2003. The spite motive and equilibrium behavior in auctions. Contrib. Econ. Anal. Pol. 2.

Roth, A.E., Malouf, M.W.K., 1979. Game-theoretic models and the role of information in bargaining. Psychol. Rev. 86, 574-594.

Selten, R., Abdolkarim, S., Abbink, K., 1999. Money does not induce risk neutral behavior, but binary lotteries do even worse. Theory Dec. 46, 211-249. 